\title{
Epigénesis del periodismo sobre el narco en México
}

\author{
Epigenesis of the journalism about the narco in Mexico
}

José Luis Arriaga Ornelas jlarriagao@gmail.com

http://orcid.org/0000-0002-0498-8461

Universidad Autónoma del Estado de México (México)

Rodrigo Marcial Jiménez roca_1960@yahoo.com.mx

http://orcid.org/0000-0002-3486-3619

Universidad Autónoma del Estado de México (México)

\section{Resumen}

Este artículo muestra la forma en que se organizó y consolidó un tipo de ejercicio informativo que hoy es boyante en México: el periodismo sobre el narcotráfico. A partir de una revisión de archivo de los trabajos periodísticos hechos en torno a tres casos emblemáticos ocurridos en la década que va de 1984 a 1994 (caso Camarena, caso Álvarez Machain y caso Posadas), el trabajo ofrece evidencia empírica de que fue en esas páginas escritas en aquel momento donde se organiza la aparición epigénica de una nueva positividad periodística en México: el narco. Los datos desplegados permiten concluir que "los periodistas del narco" son solamente uno de los distintos fenómenos en materia de ejercicio informativo que han sido provocados por el entorno de violencia delictiva en que actualmente se encuentra el país. Al final del 
documento se enlistan algunos de dichos periodistas reconocidos en México por su producción narrativa sobre el narco.

Palabras clave: Periodismo; narco; narrativa; epigénesis.

\section{Abstract}

The article shows how journalism was organized and consolidated on drug trafficking in Mexico. A review was made of the journalistic works that reported three cases that occurred in the decade from 1984 to 1993 (Camarena case, Álvarez Machain case and Posadas case) and there is evidence that it was in those pages where the appearance of a New journalistic positivity: the narco. The text concludes that narco journalists are just one of the different phenomena in journalistic practice that have been caused by the environment of criminal violence in which Mexico is currently located.

Keywords: Journalism; narco; narrative; epigenesis.

México atraviesa por una etapa crítica en materia de violencia criminal: "a partir del tercer trimestre de 2014 se registró un dramático incremento en el número de ejecuciones. Este incremento continuaba hasta el cuarto trimestre de 2017 (año que fue, bajo cualquier métrica, el más violento en la historia reciente del país)" (Guerrero, 2018: 114). Hay casi unanimidad en señalar que este comportamiento de la violencia se encuentra directamente relacionado con el tráfico de drogas, con las variaciones en el mercado de estupefacientes y con la lucha emprendida por el gobierno federal en contra de los cárteles de la droga desde 2006 (Guerrero, 2018; Pereyra, 2012; Grillo, 2012; Aguayo y Benítez, 2012).

Ejercer el periodismo en este entorno es una actividad complicada, pues en gran parte de las regiones del interior del país, en las que "hay una abierta presencia de cárteles de las drogas y grandes tasas de crímenes de alto impacto, los periodistas ejercen su labor con severas limitaciones, hostigamientos y casos frecuentes de violencia física o verbal" (Rodelo, 2009: 102). Esto ha permitido la aparición de, al menos, tres fenómenos sui géneris en el quehacer periodístico que tiene que ver con este entorno violento relacionado con la actividad delictiva:

a. La decisión de no informar, como mecanismo de seguridad (Illiades, 2017), lo cual no puede entenderse sin la presencia de un "nuevo gatekeeper" en el proceso de producción informativa 
(Gallur, 2013), que incluso puede llegar a pagar por el silencio informativo: mientras cientos de periodistas son agredidos cada año y decenas asesinados, otros deciden no poner en riesgo su vida y aceptar las imposiciones de actores ajenos a los medios, como pueden ser los líderes de grupos delictivos.

b. La cobertura de sucesos como ejecuciones, secuestros, detenciones, decomisos de droga y otros en tanto "historia policiaca" (Sierra, 2011), con un tratamiento popular de tipo nota roja, donde se da cuenta de los eventos en una tónica "apartada de su relación con los contextos políticos y sociales que la generan" (Lara y Barata, 2009: 59).

c. La hibridación de periodistas que han transitado por redacciones de diarios locales o nacionales y que se convierten en autores de libros, en los que ofrecen revelar las tramas de los cárteles de las drogas. Estos personajes tienden a apartarse de las rotativas para refugiarse en las casas editoriales y producir libros que "enjuagan y repiten lo que se dice o se sabe de oídas sobre la guerra, y esto lo sustentan, en su mayoría, con fuentes anónimas" (Illiades, 2017).

El primero de los fenómenos obligaría a hablar de situaciones derivadas de los riesgos periodísticos que se ciernen cobre los reporteros y que se han convertido en formas de censura. De ello han dado cuenta organizaciones como Article 19 (2017), Reporteros Sin Fronteras o la Fundación MEPI (2010), así como los trabajos de Solís y Prieto, 2010; Rodelo, 2009; Ramírez, 2008 y Gallur, 2013, entre otros. Este artículo no se ocupará de ello.

Tampoco será materia del presente trabajo esa especie de continuum de la nota roja que inicia con la cobertura que desde inicios del siglo XX daba la prensa a acciones como el cultivo de amapola y el tráfico de opio: "La prensa local habla ya de sembradíos de adormidera en Sinaloa y Sonora desde 1922" (Astorga, 1995: 69). De unas décadas para acá hay una cobertura a matanzas, aprehensiones, ejecuciones, desapariciones y demás sucesos relacionados con este tipo de actividades, pero con la característica de una "estructura cerrada" (Barthes, 1973), que no remite formalmente a nada fuera de sí mismo. En este tipo de ejercicio periodístico el foco de la información se pone en lo local, lo inmediato, lo unitario: el suceso, la droga, los traficantes, el ejecutado, el detenido y no en el sistema del que todos forman parte (Sierra, 2011). Se reportan los hechos -sangrientos muchas veces- pero sin explicación, ni contexto. De cómo la nota roja se transformó en México a partir de los años noventa ya han hablado otros trabajos (Arriaga, 2002), por eso este artículo no se detiene en ello.

De lo que sí se ocupa el presente artículo es de ese ejercicio periodístico que ha generado lo que llamaremos "los periodistas del narco", quienes regularmente se han formado en las 
redacciones de los diarios, para luego hacerse presentes en revistas y, finalmente, encontrar espacio de expresión en libros. Se buscará mostrar el modo en que emerge este "nuevo" tipo expresión periodística en México, identificando una época y tres casos noticiosos que terminarían por constituirse en su cimiente. Hablaremos del caso Camarena, el caso Álvarez Machain y el caso Posadas, cuyas narrativas se muestran del modo en que ocurren los procesos de epigénesis: ordenamiento de la materia, inicialmente amorfa, hacia una forma estructurada (1). Los elementos que ofrece el presente artículo abonarían a la idea de que es fundamentalmente a partir de estos tres casos como se consolida un conjunto de posibilidades discursivas que se verán repetidas una y otra vez en los escritos de los periodistas que abordan estos temas. En los cientos de páginas que en su momento se escribieron sobre los tres casos ya mencionados se estaba estructurando "la ley de lo que puede ser dicho" (Foucault, 2003: 214) acerca del narcotráfico en México, sobre los narcotraficantes, los cárteles, sus redes y modos de operación, sus acciones y consecuencias.

Para efectuar la investigación cuyos resultados se ofrecen a continuación se utilizaron como fuentes los textos periodísticos de diarios, semanarios, revistas y libros que tomaron como tema el narcotráfico, mismos que comenzaron a producir toda una narrativa en la década de los años ochenta y, luego de una década, podría decirse que habían organizado la aparición de una nueva positividad: el narco. Esta noción se constituirá en una nueva forma de hacer ver y oír los actos delictivos relacionados con el tráfico de las drogas y, en general, la delincuencia organizada (Arriaga, 2008).

\section{Emergencia del narco en el ejercicio periodístico en México}

Hay quien piensa que en México, "de repente, entre febrero y abril de 1985, el narcotráfico saltó a las primeras planas de los periódicos nacionales. Llegó para quedarse. Desde entonces, aquí sigue" (Galarza, 2013: 1). Este es un planteamiento que necesita reformularse: no puede decirse que el tráfico de drogas no existiera antes de esos años (Astorga, 1995); tampoco puede asegurarse que los diarios no daban cuenta de ese tipo de acciones (Davenport, 2003); igualmente es imposible pensar que las autoridades mexicanas no conocieran ni actuaran frente a tales ilícitos (Álvarez, 1991), pues el hecho mismo de su ilegalidad habla de una acción del Estado mexicano frente al narcotráfico. No, más bien es preciso tomar en cuenta varios factores que estimularán la conformación de lo que hemos llamado "la positividad narco". 
Es cierto que hacia la segunda mitad de la década de los ochenta del siglo XX varias cosas ocurrieron en torno de una actividad que en México tiene, por lo menos, un siglo (Astorga, 2005), el narcotráfico. Una primera cuestión es que "el régimen centralizado de poder fue sustituido por un gobierno neoliberal mínimo que dio vía libre a la expansión del mercado de drogas" (Pereyra, 2012: 434). Un segundo elemento a tomar en consideración es que "hasta mediados de la década de los ochenta el combate a la delincuencia organizada no ocupaba un lugar destacado en la agenda del gobierno mexicano" (Chabat, 2010: 22); ya para entonces existían, desde luego, grupos dedicados al tráfico de drogas, cuyo destino principal era Estados Unidos, pero éste no era un tema de la discusión pública ni un punto de conflicto con la comunidad internacional. Una tercera variable en juego en este tema es que, hasta principios de la década de los ochenta, en México la información periodística sobre seguridad pública y justicia penal predominante era la nota roja, cuyo abordaje nunca rebasaba la dimensión circunstancial de accidentes, tragedias personales y casos extraordinarios. "Los protagonistas casi exclusivos de esos contenidos eran -como en la mayoría de los medios siguen siéndololos grupos sociales etiquetados" (Lara y Barata, 2009: 65-66).

Y la cuarta variable, muy importante para entender la epigénesis de la que queremos hablar en este artículo, es que los gobiernos norteamericanos de Ronald Reagan y luego George Bush elaboraron una serie de programas antidrogas que iban mucho más allá de sus fronteras, lo cual implicaba tomar decisiones políticas sin necesariamente consultar a los países involucrados, incluido México (Bergman, 2016). Sus acciones para combatir el tráfico de drogas hacia territorio estadounidense incluían la operación de sus agencias policíacas y de inteligencia en territorio de los que identificaban como países productores y exportadores de drogas, sobre todo en América Latina. Empezaron a ser comunes las capturas de narcotraficantes latinoamericanos, acompañadas de la instrumentación de apoyo tecnológico y económico a los países latinoamericanos que se comprometieran a hacerlo, pero bajo la condición de acatar los planes y operaciones antidrogas de EU (Del Olmo, 1991). Aquí hay un elemento clave: el gobierno estadounidense estableció una agenda política, militar, diplomática, comercial, policiaca e informativa en torno al tráfico de drogas (2). Hablar de ello era no sólo posible sino pertinente.

La pertinencia que decretaba una nueva "ley de lo que puede ser dicho" vino a respaldar los trabajos periodísticos que incipientemente hablaban de narcotráfico desde hacía unos años en contados medios de comunicación. El diario Excélsior fue uno de los primeros diarios que empezó desde la década de los años sesenta a usar el término "narcotraficante", aunque las notas referidas a esos personajes se ubicaban invariablemente en la sección policiaca y/o de 
nota roja. En el mismo plano se puede ubicar al añejo periódico El Universal, que publicó notas relacionadas con el tema del tráfico de drogas desde mediados del siglo XX e incluso ha sido una fuente de información historiográfica para varios investigadores interesados en la cuestión, entre ellos Luis Astorga (2005) y Ricardo Pérez-Montfort (1999).

Igualmente se pueden referir los trabajos publicados en semanarios como Proceso y Zeta, o en periódicos como UnoMasUno, así como a periodistas en lo particular, entre los que destacó Manuel Buendía (quizá el primer periodista asesinado por hablar del narcotráfico). Pero todas las producciones periodísticas sobre el tráfico de drogas en México que puedan referirse tienen que identificar un antes y un después del caso Camarena como gran detonante de las narrativas sobre el narco.

Enrique Camarena Salazar fue un agente de la agencia antidrogas estadounidense (DEA), quien estuvo operando en México desde principios de la década del ochenta, en el marco de la política antidrogas de Estados Unidos (EU) ya referida. Una de sus principales acciones fue el seguimiento a las actividades de Miguel Ángel Félix Gallardo, José Matta Ballesteros, Ernesto Fonseca Carrillo y Rafael Caro Quintero, productores y traficantes de mariguana y amapola. EI 7 de febrero de 1985 Camerena fue raptado por gente al servicio de Caro Quintero muy cerca del Consulado de los EU en Guadalajara; fue conducido a una casa en la calle Lope de Vega, en la Colonia Jardines del Bosque, propiedad de Rubén Zuno Arce (cuñado del ex presidente de la República Luis Echeverría). Ahí fue interrogado supuestamente por Rafael Caro Quintero. Una versión del periodista Jesús Esquivel menciona que:

\footnotetext{
Una vez que tiene los ojos vendados, sale Caro Quintero de la casa y le da una patada y lo tira. 'Así te quería tener, hijo de tu chingada madre', fue lo que le dijo Caro Quintero a Camarena, según testimonio de uno de los dos testigos. Lo levantan, ya vendado, y lo meten a un cuarto de la casa que estaba destinado a las sirvientas (Esquivel, 2014: 59).
}

Camerena fue ultimado y su cuerpo sería encontrado semanas después, junto con el de su piloto, en el estado de Michoacán, cerca del pueblo de la Angostura en un rancho propiedad de Manuel Bravo Cervantes, ex diputado del partido oficial (Esquivel, 2014).

La muerte de Enrique Camarena en Guadalajara va estar precedida por dos hechos que en su momento fueron noticia en medios locales y nacionales: el que se convirtió en ese momento en el decomiso de mariguana más grande de la historia (se habla de miles de toneladas, según la fuente que se consulte), en el rancho El Búfalo, ubicado en el norteño estado de Chihuahua, el 6 de abril de 1984; y el asesinato del periodista Manuel Buendía, ultimado a tiros en el centro 
de la ciudad de México, el 30 de mayo del mismo año. El periodista Miguel Ángel Granados Chapa calificó el crimen como el primer asesinato de la narcopolítica en México (2012).

La desaparición del agente Camarena generó fuertes discrepancias entre el gobierno de México y el de EU. La presión norteamericana sobre el presidente mexicano para que esclareciera el caso fue tanta que la Procuraduría General de la República (PGR) se vio obligada a comunicar que, de acuerdo a sus investigaciones, eran un grupo de narcotraficantes nacionales los autores de los secuestros de Caramera y su piloto. El que desde las más altas esferas del gobierno mexicano y norteamericano se "diera nota" declarando sobre acciones de narcotraficantes mexicanos no sólo trajo como consecuencia la naturalización del término, sino que empezó a identificarse a varios de ellos por su nombre y, alentados por el escándalo en que se había convertido el caso, los reporteros comenzaron a indagar vida y obra de dichos personajes: Miguel Ángel Félix Gallardo, Ernesto Fonseca Carrillo, Rafael Caro Quintero empezaron a ser nombres familiares para la prensa y, consecuentemente, para la opinión pública.

Del mismo modo, cuando el director general de la DEA emitió su reporte sobre el secuestro de Camarena, se estructuró de un modo específico la positividad del objeto a observar (el narco): se trataba de una actividad -el tráfico de drogas- en la que estaban inmiscuidas autoridades policiacas, políticas y militares. Igualmente había empresarios y gente de negocios involucrados con los narcotraficantes. Esto hacía posible pensar al narco como un mundo, edificado sobre una red de vínculos que era necesario conocer. Es de este modo como la labor informativa se transformaba en la investigación y publicación de dichos vínculos y/o los modos en que se organizaba el tráfico de estupefacientes, las inmensas ganancias que dejaba y los lujos que las mismas proporcionaban a todos los involucrados. He aquí la epigénesis de los periodistas del narco, aquellos que encontraron en esta veta informativa la forma de develar aquello que permanecía oculto.

Rafael Caro Quintero (protagonista principal del caso Camarena) fue el narcotraficante del que más se ocupó la prensa en aquellos años. Por ejemplo, el periodista Jorge Mejía Prieto refirió que "Rafael Caro Quintero nació en 1956, en la Noria del Norte de Badiraguato, ranchería situada en el estado de Sinaloa. Solamente curso el primer año de escuela primaria....años más tarde se hizo amigo y socio del narcotraficante Ernesto Fonseca Carrillo" (1988: 35). En el recuento de sus andanzas Mejía publicó también que el destino de Caro Quintero se encontró marcado por el asesinato de su padre, Emilio Caro Payán, quien murió por problemas relacionados el narcotráfico. Al quedar huérfano Rafael Caro "quedó al cuidado de su tía, Manuela Caro, mujer que monopolizaba el cultivo de la goma de opio... Al lado de doña 
Manuela, Rafael conoció todos los manejos y secretos del narcotráfico" (Mejía Prieto, 1988: 36).

La mayoría de los escritores y periodistas -Méndez Asencio (1985), Mejía Prieto (1988), Shannon (1989), Scherer García (2001), Monsiváis (2004), Hernández (2014)- que escribieron sobre Caro Quintero coinciden en describirlo como iletrado y presuntuoso. Pero es un hecho que sus publicaciones contribuyeron a acrecentar la leyenda del traficante. Sobre Caro Quintero, se dijo, eran famosas las enormes pulseras de oro rematadas con diamantes y otras piedras preciosas. Fue también conocido por su personalidad de "conquistador" de mujeres. Este era el tipo de detalles en el que ahora se habrían de detener los trabajos periodísticos: decir quiénes eran los narcotraficantes, cómo vivían, cómo se aliaban o peleaban, cómo huían de la policía, cómo se apoderaban de territorios y voluntades, creando una especie de mitología (Astorga, 1995).

No era extraño, pues que amplios reportajes y libros enteros consignaran cosas como esta:

\begin{abstract}
Caro Quintero adquirió mucho poder económico que lo llevó a perder la discreción, ya que se le vio rodeado de bellas mujeres y guardaespaldas en restaurantes y discotecas de Guadalajara. Caro Quintero superó a su protector y socio "Don Neto", lo mismo en la magnitud de sus operaciones, que en el monto consecuente de sus utilidades; asociándose además con el traficante Juan José Esparragoza, alias el "Azul”, y con los contrabandistas de la cocaína y la heroína Miguel Ángel Félix Gallardo y José Ramón Matta Ballesteros (Mejía Prieto, 1988: 37).
\end{abstract}

A los ojos de la prensa ya era visible el narco. Periodísticamente hablando, ya resultaba posible sostener, por ejemplo, que "siendo Toledo Corro gobernador de Sinaloa, la mafia mexicana del narcotráfico evolucionó hasta convertirse en una gran "empresa" denominada genéricamente con el término de cártel" (Correa, 1983: 24) (lo cual consignó el semanario Proceso en su número 346). Según los diarios y semanarios mexicanos que se ocupaban del tema (3), en la década de los ochenta en Guadalajara operaban 18 familias de narcotraficantes. Y decir cómo lo hacían era tarea prioritaria. Guillermo Valdés Castellanos, en su libro Historia del narcotráfico en México (2016), da esta versión:

La estructura directiva y operativa de los narcos estaba compuesta de varios clanes familiares, entre ellos los Caro Quintero (Rafael, La Noria, Sinaloa, 1952; Miguel; su tío Javier Caro Payán, y Emilio Quintero; Los Zambada (Ismael el "Mayo, nacido en 1948, su hermano Jesús y su hijo Vicentillo); Ios Beltrán Leyva (Arturo; Badiraguato, Sinaloa 1961; 
Alfredo, Carlos y Héctor); los Carrillo Fuentes, sobrinos de Don Neto (Amado; Navolato 1954; Rodolfo y Vicente); los Guzmán Loera (Joaquín "El Chapo", Badiraguato 1957, y su hermano Arturo); los Arellano Félix (Benjamín, Ramón, Francisco Javier y Eduardo) (Valdés, 2016: 179).

Bien asentada este tipo de actividad informativa, unos años después vendría otro estímulo para atisbar nuevos confines del narco más allá de los narcotraficantes: el "caso Álvarez Machain", que era una secuela del caso Camarena. A través de este nuevo caso se generó una cantidad importante de trabajos periodísticos cuya materia informativa eran los vínculos entre los narcotraficantes y el poder político en México (4).

El médico Humberto Álvarez Macháin fue capturado en Guadalajara el 3 de abril de 1990 por un grupo de individuos al servicio de la DEA. Los hechos se registraron en su consultorio. "En el ilícito intervinieron algunos policías del estado de Guanajuato, contratados por Antonio Garate Bustamante, operador de la DEA, apoyado y autorizado por Héctor Berrellez, agente de la DEA con base en Los Ángeles, California" (Oseguera, 1991: 26). El médico fue acusado por el gobierno de EU de haber estado involucrado en el asesinato del agente de la DEA, Enrique Camarena.

Durante el juicio a Álvarez Machain en EU hubo acusaciones en contra de conocidos personajes políticos del régimen del ex presidente mexicano Miguel de la Madrid Hurtado. La revista mexicana Proceso elaboró un seguimiento puntual del juicio en contra de Álvarez Macháin, que se llevó a cabo en los meses de noviembre y diciembre de 1992, en una Corte de California. Rubén Zuno Arce fue otro de los indiciados mexicanos que comparecieron ante la Justicia norteamericana por cargos derivados del proceso contra Álvarez Machain. De hecho, la sesión de la Corte del día martes 8 de diciembre de 1992 se caracterizó porque el testigo de la fiscalía, Jorge Godoy López, inculpó a altos funcionarios y ex funcionarios del gobierno mexicano. Comentó en sus declaraciones que: "Juan Arévalo Gardoqui y Enrique Álvarez del Castillo recibieron dinero del cártel de Guadalajara. Personalmente yo se los di". La revista Proceso no sólo publicó esta declaración, sino la respuesta:

El gobierno de México, mediante la Procuraduría General de la República, descalificó ayer las expresiones dolosas y las imputaciones, que los fiscales John L. Carlton y Manuel Medrano han hecho en el juicio que se instruye a Álvarez Machain, en contra de los servidores públicos, pues están basadas en testimonios de personas contratadas para tal fin por la DEA (Luna, 1992: 11). 
En una entrevista concedida el mes de diciembre de 1992, el procurador mexicano Enrique Álvarez del Castillo respondió a las imputaciones que se le hacían declarando a la prensa que se trataba de "...afirmaciones infundadas y dolosas (...) y peor cuando éstas se apoyan en supuestos testimonios provenientes de personas totalmente descalificadas moralmente, cuyos seudotestimonios fueron obtenidos mediante auténticos sobornos..." (Rodríguez, 1992: 11).

El caso Camarena se había complicado para México, ya que después de inculpar a traficantes de drogas, como Rafael Caro Quintero, Ernesto Fonseca Carrillo, Miguel Ángel Félix Gallardo y al centroamericano Ramón Matta Ballesteros, se culpabilizaba ahora a altos ex funcionarios del gabinete del ex presidente Miguel de la Madrid.

En ese momento el caso Álvarez Machain involucró directamente a Álvarez del Castillo, que era el titular de la PGR, quizá porque éste había sido gobernador del estado de Jalisco (Loya, 1992: 9).

A Álvarez del Castillo ya se le había relacionado como protector del narcotráfico en dicho estado, incluso antes de la muerte de Camarena. De hecho el caso Álvarez Machain se llegó a editar en trabajos de investigación sobre la nota roja, como en el libro de Antonio Arellano titulado Fuera de la ley. La nota roja en México 1982-1990, en donde apareció un ensayo sobre dicho personaje. El tema ya no era solamente una cuestión policiaca, se había politizado absolutamente.

El agente de la DEA Antonio Garate Bustamante, que había planeado el secuestro de Álvarez Machain, se envalentonó y dio entrevistas a la prensa, en donde vociferó y acusó a diestra y siniestra sobre el papel jugado por políticos y ex funcionarios mexicanos. Garate Bustamante también involucró a Manuel Bartlett Díaz, uno de los funcionarios más poderosos del gobierno de Miguel de la Madrid. En entrevista con el semanario Quehacer Político, se soltó y comentó que:

Los crímenes de Manuel Buendía Téllezgirón, Carlos Loret de Mola y Enrique Camarena Salazar están ligados, sostiene el agente de la Drug Enforcement Administration, Antonio Garate Bustamante, quien acusa a Manuel Bartlett Díaz, Secretario de Gobernación en el régimen de Miguel de la Madrid Hurtado, de ser el autor intelectual de tan horrendos crímenes, porque los tres sabían de su relación con el gang del narcotráfico (Menéndez, 1990: 9).

Ante las acusaciones Bartlett Díaz comentó que "no son sino calumnias y una maniobra sucia contra México." El periodista Miguel Ángel Granados Chapa, citando el libro El Oso y el Puercoespín (2003) del ex embajador de Estados Unidos Jeffrey Davidow refiere que: "Bartlett 
estaba proscrito en la lista de invitados frecuentes en la residencia de la embajada de Estados Unidos, esto por la suposición de que al ex Secretario de Gobernación se le vinculó al secuestro y asesinato de Camarena" (Granados, 2012: 218).

De principio a fin, el juicio contra el médico Álvarez Machain tuvo un tinte político, lo cual añadió una regla discursiva más a la narrativa sobre el narco: no es concebible el poder del narcotráfico sin la complicidad política; también era necesario informar de eso (5).

Ya para 1993, cuando aparece el caso Posadas, los "periodistas del narco" estaban absolutamente dispuestos a consignar en reportajes, entrevistas, columnas y hasta libros los entretelones del caso en el que ahora se vería involucrado el Estado Vaticano, por el asesinato de su cardenal en México, Juan Jesús Posadas Ocampo. El hecho sucedió el lunes 24 de mayo de 1993 y la noticia se propagó de inmediato a través de los medios de prensa escrita, radio y televisión. Lo interesante de este caso es que ahora, desde la autoridad, desde la versión oficial sobre el caso, se recibía un discurso que se articulaba sobre la premisa que en la prensa ya había tomado carta de naturalización: los cárteles de la droga existen, operan, tienen vida propia y el asesinato del cardenal parecía sólo un daño colateral. Además, ya eran absolutamente identificables narcotraficantes de los que no se necesitaba dar ninguna explicación o contexto al nombrarlos: eran personajes públicos El "Chapo" Guzmán, los hermanos Arellano Félix o el "Güero" Palma, por citar sólo algunos.

El 25 de mayo el procurador de Jalisco, Leobardo Larios Guzmán, dio una conferencia de prensa en la cual se avocó a dar lectura a un documento en el que cronológicamente relató los hechos: "El cardenal llegó al aeropuerto en el momento, en que se desarrollaba la balacera entre el grupo de narcotraficantes en pugna, entre ellos el "Chapo" Guzmán y el "Güero" Palma y lo confundieron con el narcotraficante", según lo consignó el diario Excélsior al día siguiente. Pero pronto aparecieron contradicciones entre las declaraciones de los funcionarios judiciales y los responsables del servicio forense. Así lo apuntó el periodista del semanario Proceso Rodrigo Vera, quien difundió en una nota que "el servicio forense apuntaba en su reporte, que los disparos sobre el cuerpo del cardenal habían sido directos y en corto, así la hipótesis del fuego cruzado caía sobre sí misma". Y a partir de una entrevista realizada al médico Mario Rivera Souza, responsable del servicio forense, el periodista comentó que:

el doctor Mario Rivera Souza, con más de cuarenta años de experiencia en ese ramo, y reconocimientos internacionales... sin reparos aseguró que los disparos en el cuerpo del cardenal y su chofer fueron y en forma cruzada, de acuerdo a las entradas y salidas de los proyectiles. Además subrayó, fueron disparos a corta distancia, según él pudo observar detenidamente en la revisión del cuerpo (Vera, 1994: 44). 
La andanada de noticias y reportajes en la prensa nacional e internacional sobre la muerte del cardenal Posadas Ocampo se materializó en encabezados a primera plana sobre el tiroteo en donde había caído el cardenal Posadas. Por ejemplo, el diario Excélsior decidió un encabezado a ocho columnas en su edición del 25 de mayo de 1993 que informaba: "Asesinan a cardenal Posadas Ocampo en medio de un tiroteo".

Las autoridades federales siempre sostuvieron una sola hipótesis: la confusión. El procurador Jorge Carpizo salió al paso de las especulaciones y presentó su teoría sobre el asesinato, que fue bautizada con el nombre de Teoría Nintendo, debido a que la presentó ante la televisión utilizando un programa de cómputo desarrollado ex profeso para explicar, según él, como se desarrollaron los hechos. Dijo textualmente que:

\footnotetext{
Se trató de matar al Chapo, y tan es así que después de los disparos, que acabamos de ver, el "Chapo" sigue circulando, y se le sigue tirando. El "Chapo" pasa toda esa línea. En ese momento le han destrozado todos los cristales, a pesar de que están blindados; pero ellos se han agachado... (Aguirre y Cobián, 1993: 7).
}

Lo que argumentó el procurador fue la idea de que los pistoleros confundieron al "Chapo" con el cardenal Posadas. La explicación que detalló el procurador fue acremente cuestionada por un sector de la prensa, ya que Jorge Carpizo realizó la crónica de la fuga del "Chapo" Guzmán como si el traficante sinaloense fuera un héroe que huye de los "malos". Además en la animación computarizada que exhibió Carpizo, destacó al supuesto taxista que contribuyó -en contra de su voluntad- a la supuesta fuga del "Chapo". Por cierto el procurador nunca hizo alusión a la presencia del "Güero" Palma como participante del tiroteo. Palma había sido involucrado en las primeras pesquisas realizadas por la Procuraduría de Justicia de Jalisco, pero después ya no fue implicado. Realmente nunca se supo si verdaderamente Palma estuvo o no en el lugar de los hechos (6).

\section{Los periodistas del narco}

Dado que la investigación que dio origen al presente artículo ubicó la década que va de 1984 a 1994 como momento de la epigénesis del periodismo del narco, dentro de este lapso son varios los periodistas identificados produciendo historias que se publicaron en diarios, semanarios y libros. La mayoría son mexicanos, algunos ya fallecieron, pero también hay 
algunos extranjeros. Sus trayectorias personales son disímiles y escribieron para diferentes medios nacionales y/o se desenvolvieron como corresponsales de agencias internacionales. Entre ellos se destacan Jorge Fernández Menéndez, Jesús Blancornelas, Elaine Shannon, José Alfredo Andrade Bojorgues, Anabel Hernández, J. Jesús Esquivel y Julio Scherer García. Todos ellos redactaron reportajes y crónicas para medios como Excélsior, UnomásUno, La Jornada, Proceso, y Zeta-Tijuana. Algunos también escribieron libros, publicados por distintos sellos editoriales. A continuación se revisará brevemente cada caso.

1. Jorge Fernández Menéndez es un periodista y analista político de origen argentino, naturalizado mexicano; escribió varios libros relacionados con el tema del narcotráfico: Narcotráfico y poder (1999), El otro poder. Las redes del narcotráfico, la política y la violencia en México (2004), Las FARC en México. De la política al narcotráfico (2008) y La batalla por México. De Enrique Camarena al Chapo Guzmán (2012). Su trabajo periodístico es principalmente de denuncia y utiliza fuentes periodísticas y textos académicos para nutrir sus trabajos. También escribe para el diario Excélsior, en donde tiene una columna denominada Razones. Varias veces ha denunciado haber recibido amenazas de muerte, presumiblemente por sus artículos relacionados con el tema del narcotráfico. Sus libros son una mezcla de nota roja y reportaje de fondo.

2. Jesús Blancornelas inició su carrera periodística en la sección deportiva de El Sol de San Luis Potosí, en 1955. En 1968 emigró a Tijuana para trabajar de reportero en el periódico El Mexicano, en donde llegó a ser jefe de redacción. De 1964 a 1970 llegó a ser subdirector de La Voz de la Frontera, y de 1973 a 1976 trabajó en El Imparcial de Sonora. De estos medios fue despedido -asegura- por su actitud crítica; esto le obligó a fundar el periódico $A B C$ de Tijuana. Este personaje refiere haber recibido presiones políticas, tanto del gobierno estatal como federal por su trabajo reporteril. Blancornelas cerró el periódico $A B C$ de Tijuana en 1980 para, posteriormente, junto con Héctor "El Gato" Félix Miranda fundar el semanario ZetaTijuana. Este se imprimió en Estados Unidos, debido a que en aquella época una de las formas de represión gubernamental a los medios de comunicación críticos consistía en restringir la venta de papel periódico producido por la paraestatal Pipsa. En noviembre de 1997 sufrió un atentado a manos de sicarios del cártel de Tijuana, pero sobrevivió.

Blancornelas concedió una entrevista a la revista Proceso en octubre de 2006, en donde detalló su óptica sobre el tema del narcotráfico y su relación tirante con los Arrellano Félix. El entrevistador le pregunta: 
-La relación entre los Arellano Félix y usted no es nada sana ¿Qué lo motiva a acercarse al seno del cártel de Tijuana?

-Quiero hablar con Enedina Arellano para preguntarle si todavía están pensando en matarme. Creo que llegó el tiempo de hablar. Los hombres más rijosos del cártel ya no están. Quiero hablar con ellos para hacer esta aclaración y también por un interés periodístico..."

La entrevista revela el protagonismo de Blancornelas al buscar el contacto con el cártel de Tijuana; al mismo tiempo él se convierte en parte de la noticia ya no son los Arellano Félix los que le buscan. Por eso la revista Proceso calificó a la revista ZetaTijuana como periodismo "estridente". La relación conflictiva de Blancornelas con el cártel de Tijuana, la describió en su libro titulado El cártel: Los Arellano Félix. La mafia más poderosa en la historia de América Latina (2002). El propio periodista estima que la aparición del libro fue lo que ocasionó que los Arrellano Félix ordenaran su muerte. Otro libro publicado por él años después fue Horas extras. Los nuevos tiempos del narcotráfico (2003). Un texto que narra toda una vida -la suyadedicada a reportear la violencia generada por los traficantes de drogas. Blancornelas no murió a manos de los sicarios del cártel de Tijuana, pero sí le arrebató la vida un cáncer, que lo postró en un hospital de Tijuana durante meses.

3. Elaine Shannon es una periodista de origen estadounidense que trabajó para Newsday, Newsweek, y también para la revista Time, en donde permaneció como reportera durante veinte años. El libro más importante de Shannon sobre las drogas lleva por título Desperados. Los caciques latinos de la droga, los agentes de la ley y la guerra que Estados Unidos no puede ganar (1989). Aborda el caso Camarena y el conflicto político y diplomático que se generó entre EE.UU. y México por la muerte del agente de la DEA. En el prefacio del texto en cuestión Elaine Shannon dice: "En cierto sentido, esta obra se ocupa del problema de las drogas desde el punto de vista destacado de la DEA (Drug Enforcement Agency). Pero, como Agee habría hecho ver, la perspectiva, o el prejuicio, son míos".

Esta declaración indica la orientación del discurso de la periodista y también previene al lector sobre la procedencia de los datos que ella da sobre los narcotraficantes latinoamericanos. Su fuente principal de información son los agentes de la DEA que estaban destacados en varios países de América Latina. El libro de Shannon se destacó, como ella misma lo manifiesta, por su prejuicios y sus valoraciones personales sobre los traficantes de drogas. A lo largo del texto se pueden encontrar múltiples expresiones de discriminación y racismo en contra de los traficantes mexicanos. El libro contribuye a fortalecer lo que Astorga llamó "la mitología del narcotraficante mexicano". 
4. José Alfredo Andrade Bojorges es un abogado y periodista, originario de Tlalpujahua, Michoacán. Este periodista fue reconocido por su La Historia secreta del narco. Desde Navolato vengo (1999). En el texto referido el autor describió principalmente la trayectoria de Amado Carrillo Fuentes, también conocido con seudónimo de El Señor de los Cielos y quien fue líder del denominado cártel de Juárez. En dicho texto también apareció un personaje recurrente en las historias del tráfico de drogas en México, Joaquín Guzmán Loera, conocido también con el sobrenombre de "El Chapo".

Este texto ha sido una fuente de información, incluso para otros periodistas especializados en el tema del narcotráfico, entre ellos Diego Osorno (2009) y Anabel Hernández (2014). Andrade Bojorges relaciona directamente al Chapo Guzmán con Amado Carrillo, ya que en la década de los noventa el primero fue uno de los personajes más cercanos a El Señor de los Cielos. El libro de Bojorgues también describe el asesinato del cardenal Posadas Ocampo y la supuesta culpabilidad del "Chapo" Guzmán.

El estilo periodístico de Andrade Bojorges puede calificarse de mixtura entre nota roja, reportaje, biografía y ficción. El periodista elogia a Amado Carrillo, afirmando que: "Navegando en el mundo del 'comparezco y expongo' me di cuenta de que Amado Carrillo Fuentes daba lo mejor de sí por su familia, por su comunidad, por su país..." (Andrade, 1999: 20). Andrade Bojorges también comentó sobre la extrovertida personalidad de Amado Carrillo Fuentes y describió al personaje afirmando que:

\begin{abstract}
Amado Carrillo Fuentes no se anticipó a su porvenir ni sobrevivió a su pasado. Fue en hombre de su época, sin anacronismos ni premuras. El tiempo estuvo a su favor, los días y los años lo fueron esculpiendo hasta hacerlo un signo indispensable en el mundo delictivo...Quienes conocieron al "Señor de los Cielos" jamás olvidaron a quien aparentemente, todo sabía y todo lo podía. Para muchos era un ser omnisapiente y omnivalente, un semidiós mítico. No parecía tener mucha fuerza física, pero sí unos pies que pisaban muy firme, aunque se diga que le gustaba mucho volar... (Andrade, 1999: 23).
\end{abstract}

La apología que hace expone ante los lectores a un personaje que contribuyó a la conformación del estereotipo del clásico traficante de drogas. A la vez contribuye a la construcción del personaje-leyenda. Este periodista desapareció en 1999 y hasta el momento no se sabe nada de él, pero rumores periodísticos indicaron, que había sido "levantado" y ejecutado por haber "balconeado" el submundo del narco mexicano.

5. Anabel Hernández es una periodista mexicana que trabajó para los diarios Milenio y El Universal. También ha realizado reportajes para Reporte Índigo, Reforma y el semanario 
Proceso. Aprendió los gajes del oficio como reportera en el diario Reforma y a "buscar" la información en la calle. Se autodefinió como una periodista de investigación. Su intención manifiesta como periodista es "trabajar para dar a conocer la cultura de impunidad, que gobierna las acciones de los funcionarios corruptos en México". El periodismo de denuncia y el reportaje de investigación definieron el trabajo de dicha periodista. Sus fuentes son libros sobre el tema del narco, informes de agencias periodísticas extranjeras, informes de la PGR, declaraciones ministeriales, reportajes de otros periodistas, filtraciones clasificadas de la DEA, informes del Departamento de Estado de EE.UU., entre otras.

El libro más importante de Anabel Hernández lleva por título Los señores del narco (2014). El texto es una crónica sobre la complicidad de las élites políticas mexicanas con el crimen organizado. En el libro aparecen retratados varios personajes: traficantes, policías, militares y algunos funcionarios del gobierno (PRI-PAN). Hernández describió con profusión de fechas, datos y nombres las historias de los narcos. La aparición del libro en cuestión -según ella- le generó varios enemigos, como Genaro García Luna, quien fue el Secretario de Seguridad Pública del gobierno de Felipe Calderón (2006-2012) y al que acusó en su libro de estar al servicio del "Chapo" Guzmán. Anabel Hernández ha sido una las pocas periodistas que ha tenido la oportunidad de entrevistar en persona a Rafael Caro Quintero, personaje reconocido por su participación en el secuestro y asesinato del agente de la DEA, Enrique Camarena Salazar en 1985. La entrevista fue videograbada por TV Proceso en el mes de julio de 2016 y en ella Rafael Caro Quintero sostiene que no mató a Enrique Camarena y asegura que estaba "en el lugar equivocado". Caro también pide "perdón" a la sociedad mexicana, a la DEA y al gobierno de EE.UU y sentencia: "No estoy en guerra con nadie; 'El Chapo y El Mayo son mis amigos'. Dice que se dedicó a la siembra de mariguana porque de alguna manera había que sobrevivir" (Hernández, 2016: 10).

La entrevista realizada por Hernández a Caro Quintero expuso la trayectoria del personaje y su vínculo con el caso Camarena, así como su amistad con otros traficantes de drogas de Sinaloa. Además, Caro se eximió de futuros cargos que le podía imputar la DEA.

Anabel Hernández es actualmente una de las figuras más importantes del periodismo de denuncia en México, y ha escrito otros libros sobre la violencia en México, como México en llamas. El legado de Calderón (2012) y La verdadera noche de Iguala. La historia que le gobierno intentó ocultar (2016).

5. J. Jesús Esquivel es licenciado en periodismo y desde 1988 es corresponsal en Washington D. C., acreditado ante la Casa Blanca, el Congreso Federal y el Departamento de Estado de Estados Unidos. Trabajó como editor y productor de Televisa y fue el primer corresponsal en 
Washington de TV Azteca. Se ha desempeñado como analista político en varios programas de radio y televisión de cadenas como National Public Radio, CNN, Univisión, Al Jazeera, Telesur de Venezuela y $R C N$ de Colombia.

Este periodista ha escrito dos textos relacionados directamente con el caso Camarena y que están redactados con base en entrevistas que dice haber realizado a ex agentes de la DEA en retiro. Los libros llevan como título La DEA en México: Una historia oculta del narcotráfico contada por sus agentes (2013) y La CIA, Camarena y Caro Quintero: La historia secreta (2014). En el primer texto Esquivel realiza una breve historia de la DEA y su presencia en México. Además comenta sobre quiénes fueron los informantes de dicha agencia. En una entrevista realizada a Mike Vigil, un ex agente de la DEA, el periodista le pregunta al entrevistado lo siguiente:

\footnotetext{
- Qué hace una agente de la DEA inmediatamente después de ser asignado a México?

Mike Vigil, quien posiblemente es uno de los ex agentes de la DEA con mayor experiencia en materia de investigación en México, hace una pequeña pausa antes de contestar.

- Tener contacto con las autoridades mexicanas y armar una buena red de informantes para penetrar a los cárteles del lugar en donde te hayan asignado. Un informante de la DEA puede ser un policía municipal, estatal o federal, corrompido por el narcotráfico; un vendedor de periódicos que conoce todos los movimientos criminales de la colonia o del barrio, o bien cualquier persona. Pero la fuente secreta más valiosa de una agente estadounidense es un integrante del crimen organizado y/o de algún cártel de las drogas. En otras palabras, el informante ideal para un agente antinarcóticos de Estados Unidos es un criminal (Esquivel, 2014: 27).
}

El libro en cuestión abunda sobre las formas de operar de los agentes de la DEA en México, sobre sus contactos con "soplones", sobre las informaciones anónimas que les hacen llegar, sobre sus vínculos con políticos y autoridades judiciales y también sobre las operaciones que han realizado en México.

En el segundo libro de Esquivel, titulado La CIA, Camarena y Caro Quintero (2014), el periodista describe la participación de los traficantes del cártel de Guadalajara en el secuestro y asesinato del agente de la DEA, Enrique Camarena, pero también la supuesta participación de la agencia estadounidense CIA en el complot para desaparecer a dicho agente. La base de la información de este libro fueron también entrevistas a ex agentes de la DEA, quienes fueron cuestionados por Esquivel para dar su versión sobre el asesinato de Camarena y la 
participación de varios personajes: narcos, políticos y agentes de la CIA. En su libro consigna que uno de estos ex agentes entrevistados manifestó que:

\begin{abstract}
...una gran parte de los documentos recopilados en la "Operación Leyenda" jamás saldrá a la luz pública -el Departamento de Justicia de Estados Unidos etiquetó centenares de éstos como top secret y los archivó como riesgosos para la seguridad nacional-, por razón de que refieren, primero, la participación indirecta de la CIA en el secuestro, tortura y asesinato del agente antinarcóticos de Estados Unidos en Guadalajara; y, segundo, su involucramiento tanto con el narcotráfico y políticos mexicanos que colaboraban con Rafael Caro Quintero y Ernesto Fonseca Carrillo, entre otros, con las guerrillas centroamericanas (Esquivel, 2014:
\end{abstract} 169).

Además, el texto referido agrega datos sobre la Dirección Federal de Seguridad (DFS) mexicana y su participación in-directa en el caso Camarena. Da cuenta también del asesinato del periodista Manuel Buendía, personaje que ya había documentado la participación encubierta de la CIA en México. El relato de Esquivel parece por momentos ser un thriller: suspenso, héroes y villanos aparecen en este texto muy cercano al estilo de la novela "negra" y no al periodismo. La supuesta participación de la CIA en el caso Camarena, según Esquivel, sólo evidenció las intrigas intestinas de las agencias estadounidenses. El libro de Esquivel generó más interrogantes y dudas sobre el caso Camarena que quizá no puedan saberse por el momento.

6. Julio Scherer García fue una persona de gran prestigio en el gremio de los periodistas por ser el fundador y director del semanario Proceso, después de su polémica salida el diario Excélsior. Aunque no puede calificarse como un periodista especialista en el narcotráfico, su trabajo como entrevistador ha sido reconocido por propios y extraños. Este periodista entrevistó a varios personajes del narco. Dos libros destacan de este escritor-periodista: Máxima seguridad: Almoloya y Puente Grande (2001) y La reina del pacífico: es la hora de contar (2008). En el primer texto Scherer realiza 17 entrevistas a varios reclusos de los penales de máxima seguridad en México, entre los que destacan Rafael Caro Quintero, Héctor Luis Palma "El Güero" y Miguel Ángel Félix Gallardo (los tres ligados al cártel de Guadalajara) y la hecha a Francisco Arrellano Félix, miembro del cártel de Tijuana.

A raíz de la entrevista que le hace Scherer a Rafael Caro Quintero, el periodista comenta:

Se supo entonces de la vanidad de Caro Quintero. Millonario, apuesto, personaje inédito que rozó la leyenda, fue tema de corridos. Caro Quintero daba entrevistas y se gozaba con 
sus fotografías en los periódicos. Su sonrisa, anchos y fuertes los dientes, se correspondía con la de un actor (Scherer, 2011: 179-180).

La descripción hace énfasis para mostrar a Caro Quintero como un personaje fascinante, estrafalario y extrovertido. Scherer fue también otro de los periodistas que contribuyeron a mitificar a este traficante. En este texto, el periodista se convierte también en protagonista: él es el que guía la entrevista, el que cuestiona, el que indaga, el que transcribe.

En el diálogo establecido entre Scherer y el traficante. Este le pegunta a Caro:

- ¿Trabajó para Arévalo Gardoqui, secretario de la Defensa? Miles de jornaleros estaban bajo sus órdenes y había soldados en "El Búfalo".

-Para nada. Yo no tengo relación con toda esa gente.

- ¿De qué complicidades se valió para hacer tanto como hizo?

- A puro valor. A puro valor tonto, porque no era otra cosa: Nada más ir por allí para ver si pegaba, ¿me entiende? (Scherer, 2011: 180).

En el mismo libro aparecen otros personajes ligados al tráfico de drogas, como Oliverio Chávez Araujo, Mario Villanueva Madrid (ex gobernador de Quintana Roo), Jaime Valencia, Arturo Martínez Herrera, "El Texas", entre otros. Scherer García fue prolífico en su escritura, ya que escribió varios libros sobre problemas contemporáneos de México. Fue reconocido por su gusto por las entrevistas. Este periodista falleció el 7 de enero de 2015.

Otros escritores y periodistas que han contribuido con sus textos a la documentación del tema del narcotráfico mexicano en el momento de su epigénesis son: Carlos Monsiváis, Miguel Ángel Granados Chapa, Héctor Aguilar Camín, Héctor Moreno Valencia, Diego Enrique Osorno, Rodrigo Vera, Jorge Mejía Prieto, entre otros.

\section{Conclusiones}

La metáfora de la epigénesis nos permite pensar en el desarrollo de un tipo de ejercicio periodístico que hoy se ha consolidado en México y que se ocupa del narco. Esta noción incluye dar cuenta de eventos, vincularlos a actores, a sucesos previos, a acciones policiacas, a políticas públicas, a personajes de distintas esferas sociales, económicas y políticas, así como describir de manera detallada la vida de narcotraficantes, sicarios, operadores financieros, encubridores, protectores, sus mujeres, sus herencias, sus propiedades. Todo eso 
y más cabe en el narco: es una positividad que delimita un campo discursivo que no existía tal como ahora se le conoce antes de que los casos Camarena, Álvarez Machain y Posadas fueran materia de páginas y páginas de material periodístico.

La organización y estructuración de la narrativa, de la ley de lo que puede ser dicho, de la noción misma de narco, no fue algo planeado ni estaba ya hecho y esperaba agazapado para crecer y operar. Por eso es posible de hablar de un proceso de epigénesis en el que los periodistas comenzaron a escribir sobre algunos casos específicos de obligada notoriedad y, jalando el hilo, fueron encontrando las hebras de las que hoy está hecha la tela que día a día cortan los periodistas del narco.

La selección de los tres "casos" abordados en este texto permite identificar un hilo de continuidad entre el primer momento en que el gobierno mexicano tuvo que pronunciarse al respecto del tráfico de drogas frente a su poderoso vecino EU (a propósito del caso Camarena) y el momento -una década más tarde- en que tuvo que promulgar una Ley Federal contra la Delincuencia Organizada y hacer de la lucha contra el narcotráfico su principal política pública, hasta llegar a 2006 en que el presidente de la República le declara la guerra a los cárteles de la droga. Las secuelas violentas de esta acción gubernamental aún hoy se padecen en México y la narrativa sobre el narco sigue permeado la vida social y cultural de los mexicanos.

\section{Notas}

(1) En el campo de la biología, específicamente en el tema del desarrollo embriológico, hay dos posturas fuertes: la epigénesis y el preformacionismo. La hipótesis de la epigénesis concibe el fenómeno del desarrollo como un proceso de ordenamiento de la materia embrionaria, inicialmente amorfa, hacia una forma biológica estructurada. Es decir, el desarrollo del ser vivo no se piensa sólo como crecimiento, sino como un proceso de estructuración del embrión amorfo bajo principios orgánicos de organización. Por su parte, la postura del preformacionismo es que la organización del ser viviente está presente en el embrión en miniatura (Vecchi y Hernández, 2015). Para este trabajo parece pertinente la metáfora de la epigénesis porque ayuda a entender la emergencia de una narrativa sobre el narco que no pre-existía antes de los casos que se abordan en el artículo.

(2) La estrategia para colocar al tráfico de drogas más allá de un asunto de aplicación legal se inició en 1986 por iniciativa de la National Security Decision Directive (NSDD) 221, firmada por el presidente Ronald Reagan. El documento instruyó a los organismos militares de EE.UU., para hacer uso de amplios recursos para combatir el narcotráfico internacional. Así como la planeación y ejecución de operativos antinarcóticos y el entrenamiento de fuerzas militares especiales. La vinculación narcotráfico/seguridad nacional se consolidó a mediados de la década de los ochenta, con el gobierno de Reagan. Por lo menos tres presidentes norteamericanos, Nixon, Reagan y Bush, declararon guerras contra las drogas (Aguayo y Bagley, 1990). 
(3) Entre los diarios mexicanos que reportaban las actividades de los traficantes sinaloenses en la década de los ochenta, se destacan La Jornada, El Universal y el semanario Proceso.

(4) Específicamente el caso Camarena fue abordado por varios periodistas y académicos, entre ellos Luis Mendez Asensio (1985), Jorge Mejía Prieto (1988), Elaine Shannon (1989), Sergio García Ramírez (1989), Jorge Fernández Menéndez (1997), Luis Astorga (2005), Diego Enrique Osorno (2009), Miguel Ángel Granados Chapa (2012), Guillermo Valdés Castellanos (2013), J. Jesús Esquivel (2014) y Anabel Hernández (2014), entre otros.

(5) El caso Álvarez Machain fue retomado por algunos reporteros, investigadores y políticos, entre quienes destacan Juan Antonio Oseguera (1991), Rodolfo Medina (1991), Ignacio Ramírez (1992), Lucía Luna (1992), Beatriz Jhonston (1992), Antonio Arellano (1992), Carlos Salinas de Gortari (2000) y Jesús Blancornelas (2012).

(6) En lo que hace al caso Posadas, apareció descrito en varios textos de reporteros, investigadores y ex funcionarios, entre ellos Rodrigo Vera (1994), Eduardo Valle (1995), José Alfredo Andrade Bojorges (1999), Héctor Moreno Valencia y José Alberto Villasana (2002), Jorge Carpizo y Julián Andrade (2002), Froylán Enciso (2010), y Anabel Hernández (2014).

\section{Bibliografía}

Aguayo, S. y Bagley, B. (1990). En busca de la seguridad perdida. Aproximaciones a la Seguridad Nacional Mexicana. México: Siglo XXI.

Aguayo, S. y Benítez, R. (2012). Atlas de la defensa y seguridad de México. México: CASEDE.

Aguirre, A. y Cobián F. (5 de junio de 1993). El gobierno en entredicho por una serie de curiosas "coincidencias". Proceso, 866, pp. 7-8.

Álvarez, A. J. (1991). Tráfico y consumo de drogas: una visión alternativa. México: UNAM.

Andrade, J. A. (1999). La historia secreta del narco. Desde Navolato vengo. México: Océano.

Arellano, A. et al. (1992). Fuera de la ley. La nota roja en México 1982-1990. México: Cal y Arena.

Arriaga, J. L. (2002). Colombianización o mexicanización periodística. La nota roja en los noventa. Revista Mexicana de Comunicación, 14(75), pp. 41-47.

Arriaga, J. L. (2008). El discurso de la delincuencia organizada. Análisis de su repercusión en el ejercicio del poder. El Cotidiano, 152, pp. 5-14.

Astorga, L. (1995). Mitología del narcotraficante en México. México: UNAM/Plaza y Valdés.

Astorga, L. (2005). El siglo de las drogas. México: Plaza y Janés.

Article 19 (2017). Primer semestre de 2017: 1.5 agresiones diarias contra periodistas en México. Recuperado de https://articulo19.org/informesemestral2017/

Barthes, R. (1973). La estructura del suceso. En Ensayos Críticos (pp. 225-236). Barcelona: Six Barral.

Bergman, M. (2016). Drogas y narcotráfico y poder en América Latina. México: FCE. 
Blancornelas, J. (2002). El cártel. Los Arellano Félix, la mafia más poderosa de América Latina. México: Plaza y Janés.

Blancornelas, J. (2003). Horas Extra: Los nuevos tiempos del narcotráfico. México: Plaza y Janés.

Blancornelas, J. (2005). En estado de alerta. Los periodistas y el gobierno frente al narcotráfico. México: Plaza y Janés.

Chabat, J. (2010). La respuesta del gobierno de Felipe Calderón al desafío del narcotráfico: entre lo malo y lo peor. En Alvarado, A. y Serrano, M. Los grandes problemas de México, Vol. XV (pp. 21- 39). Seguridad Nacional y Seguridad Interior, México: EI Colegio de México.

Correa, G. (18 de junio de 1983). Sus socios: banqueros y empresarios. En Sinaloa "orden a través del terror", consigna de Toledo Corro. Proceso, 346, pp. 24-26.

Davenport, R. (2003). La búsqueda del olvido: Historia global de las drogas. México: F.C.E.

Del Olmo, R. (1991). El discurso del narcotráfico y sus consecuencias en América Latina. En Álvarez, A. J. Tráfico de drogas: Una visión alternativa. México: ENEP-Acatlán/UNAM.

Esquivel, J. (2014). La CIA, Camarena y Caro Quintero. México: Grijalbo.

Esquivel J. (2013). La DEA en México. Una historia del narcotráfico contada por los agentes. México: Grijalbo.

Fernández, J. y Salazar, A. M. (2008). El enemigo en casa; drogas y narcomenudeo en México. México: Taurus.

Fernández, J. (1997). Narcotráfico y poder. México: Rayuela Editores.

Foucault, M. (2003). La arqueología del saber. México: Siglo XXI.

Fundación MEPI (2010). México: la nueva espiral del silencio. Recuperado de https://ciperchile.cl/2010/11/19/mexico-la-nueva-espiral-del-silencio/

Galarza, G. (10 de agosto de 2013). 1985, el año que se desató el narco. Excélsior. Recuperado de https://www.excelsior.com.mx/nacional/2013/08/10/913019

Gallur, S. (2013). La intimidación como estrategia: presiones, amenazas y agresiones contra los periodistas en México, 1998-2010. Contribuciones a las Ciencias Sociales. Recuperado de www.eumed.net/rev/cccss/26/intimidacion.html

Gallur, S. (diciembre de 2013). 2007-2011, un nuevo "Gatekeeper" en el periodismo en México: los medios de comunicación ante el dilema del 'Plata o Plomo. Contribuciones a las Ciencias Sociales. Recuperado de www.eumed.net/rev/cccss/26/gatekeeper.html García, S. (1089). Narcotráfico: un punto de vista mexicano. México: Porrúa. 
Granados, M. Á. (2012). Buendía. El primer asesinato de narcopolítica en México. México: Grijalbo.

Grillo, I. (2012). El Narco. New York: Bloomsbury Press.

Guerrero, E. (2018). La segunda ola de violencia. Nexos, 484, pp. 35-48.

Hernández, A. (2012). México en llamas: El legado de Calderón. México: Grijalbo.

Hernández, A. (2014). Los señores del narco. México: DeBolsillo.

Hernández, A. (2016). La verdadera noche de Iguala: La historia que el gobierno intentó ocultar. México: Grijalbo.

Hernández, A. (23 de julio de 2016). Caro Quintero desde la clandestinidad: Yo no maté a Enrique Camarena. Proceso, 2073.

Illiades, E. (2017). El periodismo en los tiempos del narco. Nexos, 469, pp. 52-60.

Lara, M. y Barata, F. (2009). Nota(n) Roja. México: Debate.

Loya, S. (5 de diciembre de 1992). Álvarez del Castillo sospechoso de proteger al narco, desde 1983. Proceso, 840, pp. 9-10.

Luna, L. (20 de junio de 1992). En el caso de Álvarez Macháin, la cancillería protesta y la Procuraduría guarda silencio. Proceso, 816, p. 11.

Mejía Prieto, J. (1988). México y el narcotráfico. México: Editorial Universo.

Méndez, L. (1985). Caro Quintero al trasluz: Más allá de la mexican connection. México: Plaza y Janés.

Menéndez, E. (24 de septiembre de 1990). Entrevista a Antonio Gárate. Quehacer político, 471, pp. 9-10.

Monsiváis, C. et al. (2004). Viento Rojo: diez historias del narco en México. México: Plaza y Janés.

Moreno, H, y Villasana, A. (2002). Sangre de mayo: El homicidio del cardenal Posadas Ocampo. México: Océano.

Oseguera, J. A. (1991). El truculento Caso Álvarez Macháin. Contenido, 337, pp. 25-29.

Pereyra, G. (2012). México: violencia criminal y "guerra contra el narcotráfico". Revista Mexicana de Sociología, 74(3), pp. 429-460.

Pérez-Montfort, R. (1999). Yerba, goma y polvo. México: Conaculta/INAH/ERA.

Pérez, M. (1985). La otra cara de Caro Quintero. México: Publicaciones y Ediciones Oro.

Ramírez, D. (2008). La libertad de expresión en México amenazada por las agresiones a periodistas y la concentración de medios. El Cotidiano, 23(150), pp. 47-52.

Reporteros sin fronteras (2017). Balance de periodistas asesinados, detenidos, secuestrados y desaparecidos en el mundo en 2017. Recuperado de https://www.rsf- 
es.org/news/informes-balance-anual-2017-65-periodistas-asesinados-326encarcelados/

Rodelo, F. V. (2009). Periodismo en entornos violentos: el caso de los periodistas de Culiacán, Sinaloa. Comunicación y Sociedad, 12, pp. 101-118.

Rodríguez, I. (12 de diciembre de 1992). Álvarez del Castillo atribuye las imputaciones "a los puestos que he ocupado, lisa y llanamente". Proceso, 841, p. 11.

Scherer, J. (2001). Máxima seguridad: Almoloya y Puente Grande. México: Nuevo SigloAguilar.

Shannon, E. (1989). Desperados: Los caciques latinos de la droga, los agentes de la ley y la guerra que Estados Unidos no puede ganar. México: Lasser Press.

Sierra, A. (2011). ¿Hay una narrativa periodística independiente sobre las drogas? Las curiosas paradojas de la cobertura del narcotráfico. Cobertura del narcotráfico y del crimen organizado en Latinoamérica y el Caribe. Austin: Knight Center for Journalism in the Americas.

Solís, B. y Prieto, I. (marzo de 2010). Agresiones a la libertad de expresión en México. Chasqui. Revista Latinoamericana de Comunicación, 109, pp. 43-47. Recuperado de file:///C:/Users/Cecilia/Downloads/Dialnet-

AgresionesALaLibertadDeExpresionEnMexico-5791150.pdf

Valdés, G. (2016). Historia del narcotráfico en México. México: Aguilar.

Vecchi, D. y Hernández, I. (2015). Epigénesis y preformacionismo: radiografía de una antinomia inconclusa. Scientiæ Zudia, 13(3), pp. 577-97.

Vera, R. et al. (1994). El asesinato del cardenal, ¿Un error? México: Planeta. 